\title{
Effect and mechanism of propranolol on promoting osteogenic differentiation and early implant osseointegration
}

\author{
YUPENG WU $^{1,2}$, QI ZHANG ${ }^{2,3}$, BAODONG ZHAO ${ }^{1,2}$ and XIAOJING WANG ${ }^{1,2,4}$ \\ ${ }^{1}$ Department of Oral Implantology, The Affiliated Hospital of Qingdao University; ${ }^{2}$ School of Stomatology, \\ Qingdao University; ${ }^{3}$ Department of Orthodontics, The Affiliated Hospital of Qingdao University, Qingdao, \\ Shandong 266000; ${ }^{4}$ State Key Laboratory of Military Stomatology, Xi'an, Shaanxi 710000, P.R. China
}

Received January 4, 2021; Accepted June 9, 2021

DOI: $10.3892 /$ ijmm.2021.5024

\begin{abstract}
The present study aimed to investigate the effect of $\beta$-receptor blocker propranolol on early osseointegration of pure titanium implants and the underlying molecular regulatory mechanisms. An implant osseointegration model using the tibial metaphysis of New Zealand rabbits was established. The rabbits were divided into control and low-, medium- and high-dose propranolol groups. The formation of implant osseointegration was detected by X-ray scanning. Mesenchymal stem cells (MSCs) and osteoblasts (OBs) were isolated and cultured in vitro, isoproterenol was supplemented to simulate sympathetic action and propranolol was subsequently administrated. The effect of propranolol on cell proliferation and osteogenic differentiation were assessed by EdU, flow cytometry, alizarin red staining and alkaline phosphatase (ALP) detection. The expression levels of bone morphogenetic protein (BMP)2, RUNX family transcription factor (RunX)2, collagen (COL)-1, osteocalcin (OCN) and $\beta 2$-adrenergic receptor (AR) were detected by immunofluorescence, reverse transcription-quantitative PCR and western blot assay. Propranolol effectively promoted implant osseointegration in vivo, facilitated proliferation of OBs, inhibited proliferation of MSCs and enhanced osteogenic differentiation of OBs and MSCs. The calcium content and ALP activity of cells treated with propranolol were markedly higher than in the control group. Propranolol also elevated mRNA and protein expression levels of BMP2, RunX2, COL-1 and OCN in tissue and cells, and decreased the expression of $\beta 2-\mathrm{AR}$. The present study demonstrated that the $\beta$-receptor blocker propranolol promoted osteogenic differentiation of OBs and MSCs and enhanced implant osseointegration. The present
\end{abstract}

Correspondence to: Professor Xiaojing Wang, Department of Oral Implantology, The Affiliated Hospital of Qingdao University, 59 Haier Road, Laoshan, Qingdao, Shandong 266000, P.R. China E-mail:wangxj_amy@yahoo.com

Key words: propranolol, osteogenic differentiation, implant, osteoblast, mesenchymal stem cell study provided a novel insight into the application and regulatory mechanisms of propranolol.

\section{Introduction}

The occurrence of defects and deformity of bone tissue affects normal function and patient mobility (1). Severe cases may also result in psychological problems for patients (1). Multiple treatment options have been available in the past, including bone transplantation (either autologous or allogeneic) and the application of bone substitute materials (2). However, these methods have disadvantages, including rejection, high surgery costs, limited availability of bone, surgical trauma and complicated surgery (3), which result in limited clinical application. Two fundamental processes, bone formation and resorption, are involved in bone metabolic formation, which leads to decreased bone formation and mass; the application of $\beta$-receptor blocker propranolol significantly increases bone formation and bone mass $(4,5)$.

As the effects of the sympathetic nervous system on bone remodeling and healing are complex and extensive, the underlying mechanism has not yet been fully recognized (6). Numerous experiments have investigated the effect of propranolol, a sympathetic blocker drug, on bone metabolism (7-9). To the best of our knowledge, however, few reports have illustrated the effect and mechanism of propranolol on proliferation of osteoblasts (OBs) and bone resorption of osteoclasts (OCs). OBs are derived from bone marrow-derived stem cells (BMSCs); OBs generate bone matrix during bone formation and release diverse bioactive substances to regulate and control the function of OCs $(10,11)$. The stimulation of the sympathetic nervous system increases bone resorption and inhibits bone formation (12). This mechanism is associated with the activity of $\beta 2$-adrenergic receptors (ARs) on OBs. Takeda et al (13) confirmed the presence of $\beta 2$-ARs (and absence of other adrenoceptor subtypes) on OBs using reverse transcription-quantitative (RT-q)PCR and northern blotting in OBs. The most frequently administered drugs for hypertension and cardiovascular disease are $\beta 2$-AR blockers. A previous study demonstrated the effect of $\beta 2$-AR blockers in skeleton tissue (7). AR agonists promote bone resorption in mice (7). Systemic application of $\beta$-AR agonists decreases bone formation and mass, while the opposite result has been obtained 
using the $\beta$-AR blocker propranolol (14-16). To the best of our knowledge, however, the effects and regulatory mechanisms of propranolol on OBs and MSCs have not been fully explored. Therefore, the present study aimed to investigate whether the $\beta$-AR blocker propranolol promotes osteogenic differentiation of OBs and MSCs and enhances osseointegration of implants. OBs and MSCs were treated with propnaolol and the effects on cell proliferation and osteogenic differentiation and expression levels of osteoblast-associated proteins were detected. The present study also aimed to serve as a basis for further investigation of the mechanisms and effects of propranolol on implant osseointegration.

\section{Materials and methods}

Model establishment of implantosseointegration. The present animal experiment was performed in strict accordance with the regulations of the Ethics Committee of The Affiliated Hospital of Qingdao University (approval no. 201905036). A total of 32 healthy male New Zealand white rabbits (age, 5-6 months; weight $\sim 3.5 \mathrm{~kg}$ ), purchased from Qingdao Kangda Biological Technology Co., Ltd., were randomly divided into four groups ( $\mathrm{n}=8 /$ group): Control and low- $(0.1 \mathrm{mg} / \mathrm{kg})$, medium- $(1 \mathrm{mg} / \mathrm{kg})$ and high-dose propranolol $(10 \mathrm{mg} / \mathrm{kg})$. Rabbits were housed in sterile cages at $22^{\circ} \mathrm{C}$ and relative humidity of 50-60\%, with $12 \mathrm{~h} \mathrm{light/dark} \mathrm{cycle} \mathrm{and} \mathrm{free}$ access to fodder and sterile water. All rabbits were acclimatized for 7 days before the operation. The anesthetic protocol was based on the Guide for Care and Use of Laboratory Animals (17). For anesthesia, xylazine hydrochloride (Jilin Province Huamu Animal Health Products Co., Ltd.) at $5 \mathrm{mg} / \mathrm{kg}$ was intramuscularly injected, followed by slow intravenous injection of 3\% pentobarbital sodium (Sigma-Aldrich; Merck $\mathrm{KGaA}$ ) at $24 \mathrm{mg} / \mathrm{kg}$. Subcutaneous propoanolol injections were administered to the propranolol groups close to the surgical site preoperatively and an equal amount of normal saline was given to the control group for 28 successive days. Animals from each group subsequently received conventional surgical cavity preparation at the metaphysis of the tibia and two pure titanium implants (diameter, $3.4 \mathrm{~mm}$; length; $8.0 \mathrm{~mm}$ ) were inserted using an implant machine, one in each hindleg. On days 1-3 postoperatively, rabbits in each group were subcutaneously injected with buprenorphine hydrochloride $(0.03 \mathrm{mg} / \mathrm{kg})$ and doxycycline $(3.2 \mathrm{mg} / \mathrm{kg})$ and all healed well following surgery. Bone tissue binding to implants and absorption was observed through X-ray examinations. Then, rabbits in each group were sacrificed with a lethal dose of pentobarbital sodium $(100 \mathrm{mg} / \mathrm{kg})$ by intravenous injection and the intact tibia tissue was removed for subsequent experiments.

Extraction of MSCs. Isolation, culture and characterization of MSCs by cell surface markers detection and multi-lineage differentiation were performed as described previously by Farahzadi et al $(8,9)$ and Fathi et al $(18,19)$. Two laboratory rabbits were sacrificed and placed in $75 \%$ alcohol at room temperature for $15 \mathrm{~min}$. Following separation on a clean bench under aseptic conditions, the tibia and femur of rabbits were placed into a beaker supplemented with PBS solution. The connective tissue and periosteum were removed immediately and the medullary cavity was washed with serum-free Dulbecco's modified eagle medium (DMEM) in a syringe and transferred into a centrifuge tube containing DMEM with $15 \%$ fetal bovine serum (FBS; both HyClone; Cytiva). When the medullary cavity turned white, ultrasound shaking at room temperature was performed at $240 \mathrm{x} g$ for $5 \mathrm{~min}$. The supernatant was discarded and high-glucose DMEM containing 15\% FBS was added for cell suspension preparation. The samples were planted in a culture flask while being blown evenly. The culture medium was refreshed after $24 \mathrm{~h}$ and replaced every 2-3 days. Experiments were performed using third passage cells.

OBs isolation and culture. Isolation and culture of OBs were performed as described by Zhao et al (20). New Zealand rabbits were anesthetized by intravenous injection of pentobarbital sodium. The femur was subsequently removed and treated as aforementioned. The marrow was extracted from cleaned bones using DMEM supplemented with 15\% FBS (HyClone; Cytiva) and incubated at $37^{\circ} \mathrm{C}$ with the medium replaced every 3 days. Once the cells were $50 \%$ confluent, the medium was replaced with DMEM containing 10\% FBS and $1 \%$ penicillin + streptomycin (all HyClone; Cytiva). The cells were harvested after reaching $80-90 \%$ confluence using $0.25 \%$ trypsin. Experiments were performed using third passage cells.

Alizarin red staining. MSCs or OBs were cultured in DMEM containing $50 \mathrm{nM}$ isoproterenol to simulate the effects of the sympathetic nerve (21). Following $24 \mathrm{~h}$ culture in DMEM, MSCs or OBs were cultured in osteogenic differentiation medium [5 mM $\beta$-glycerophosphate, $50 \mu \mathrm{g} / \mathrm{ml}$ ascorbic acid phosphate and $10 \mathrm{nM}$ dexamethasone (all Sigma-Aldrich; Merck KGaA) in DMEM supplemented with $15 \%$ FBS] containing $50 \mathrm{nM}$ isoproterenol and propranolol at different concentrations for 7-day induction at $37^{\circ} \mathrm{C}$. Mineralized nodule alizarin red staining was subsequently performed. The original culture medium was discarded and PBS solution was used for three cycles of washing. Subsequently, $4 \%$ paraformaldehyde was used for fixation at room temperature for $20 \mathrm{~min}$. Finally, the PBS solution was used to rinse cells. Cells were stained with $0.1 \%$ alizarin red dye for $30 \mathrm{~min}$ at $37^{\circ} \mathrm{C}$, washed with running water and examined under a light microscope at $\times 200$ magnification.

Alkaline phosphatase (ALP) staining. ALP staining was performed using the Gomori modified calcium-cobalt method, as previously described Huang et al (22). Following 3 weeks of induction, MSCs or OBs were inoculated into a petri dish (density, $\left.2 \times 10^{4}\right)$. Following removal of the original culture medium, cells were fixed with $95 \%$ ethanol at room temperature for $10 \mathrm{~min}$, and then incubated with incubation buffer (5 3\% sodium $\beta$-glycerophosphate, $52 \%$ sodium barbiturate, 10 distilled water, $102 \% \mathrm{CaCl}_{2}$ and $1 \mathrm{ml} 2 \% \mathrm{MgSO}_{4}$ ) at $37^{\circ} \mathrm{C}$ for $4 \mathrm{~h}$. Substrate solution was subsequently added to the petri dish, covered with hydrophobic membrane, incubated in a $37^{\circ} \mathrm{C}$ oven in the dark for $15 \mathrm{~min}$ and washed. Finally, dye solution was added for staining at room temperature for $3 \mathrm{~min}$ and samples were washed with running water and examined under a light microscope at x200 magnification. 
Cell proliferation assessment via EdU assay. EdU assay was performed as described by Shen et al (23). Briefly, MSCs or OBs $\left(1 \times 10^{7}\right)$ were cultured at $37^{\circ} \mathrm{C}$ in 6 -well plates overnight. Cells were supplemented with $\mathrm{EdU}(10 \mu \mathrm{M})$ and incubated at $37^{\circ} \mathrm{C}$ for $2 \mathrm{~h}$. After DMEM was removed, the cells were fixed with $1 \mathrm{ml} 4 \%$ paraformaldehyde for $15 \mathrm{~min}$ at room temperature. After fixing medium was removed, cells were washed 3 times by adding $1 \mathrm{ml} /$ well washing solution (3-5 min each). The washing solution was discarded. Then, $1 \mathrm{ml}$ PBS containing $0.3 \%$ Triton $\mathrm{X}-100$ was added to each well and incubated at room temperature for $10-15 \mathrm{~min}$. The cells in each well were washed with $1 \mathrm{ml}$ washing solution 1-2 times (3-5 min each). Then, endogenous peroxidase blocking solution was added for incubation at room temperature for $20 \mathrm{~min}$ to inactivate endogenous peroxidase activity. The cells were then rinsed with washing solution 3 times ( 2 min each) and visualized via a fluorescent microscope (Olympus Corporation) at x200 magnification.

Cell proliferation assessment via flow cytometry. To determine cell proliferation, BrdU assay was performed as described by Heo et al (24). The MSCs or OBs (density, $1.5 \times 10^{5} / \mathrm{ml}$ ) were inoculated in a 35-mm-diameter culture dish for 1 day at $37^{\circ} \mathrm{C}$ and synchronized in DMEM containing $0.4 \%$ FBS for 3 days until most cells entered the $\mathrm{G}_{0}$ phase. Cell proliferation was measured by a BrdU Staining kit for Flow Cytometry (cat. no. 8811-6600-42; Invitrogen; Thermo Fisher Scientific, Inc.), according to the manufacturer's instructions. Anti-BrdU FITC was added and incubated at $37^{\circ} \mathrm{C}$ for $40 \mathrm{~min}$. The culture medium was discarded. The cells were collected into a flow tube and centrifugated at room temperature and $350 \mathrm{x}$ g for $5 \mathrm{~min}$. The supernatant was discarded. Each tube was fixed at room temperature with $1 \mathrm{ml} 4 \%$ paraformaldehyde for $15 \mathrm{~min}$ and centrifugated at room temperature and $600 \mathrm{x}$ g for $10 \mathrm{~min}$. The supernatant was discarded. After washing, 2 glycine and $1 \mathrm{ml} 0.5 \%$ triton was added to each tube and incubated at $37^{\circ} \mathrm{C}$ for $10 \mathrm{~min}$. Following washing with PBS, the cells were resuspended and detected by BD LSRFortessa Flow Cytometer (BD Biosciences). Data was analyzed using CytExpert 2.3 software (Beckman Coulter, Inc.).

Wound healing assay. MSCs or OBs were seeded into 6-well plates at a cell density of $5 \times 10^{5} / \mathrm{ml}(500 \mu \mathrm{l} /$ well $)$ and cultured at $37^{\circ} \mathrm{C}$ for $24 \mathrm{~h}$ in RPMI-1640 complete growth medium (Invitrogen; Thermo Fisher Scientific, Inc.) to form an $80 \%$ confluent monolayer, which was scratched using the tip of a $10-\mu 1$ pipetting gun. Cells were washed three times with PBS and incubated for $48 \mathrm{~h}\left(37^{\circ} \mathrm{C} ; 5 \% \mathrm{CO}_{2}\right)$ in serum-free DMEM (HyClone; Cytiva). The cells were observed and photographed at 24 and $48 \mathrm{~h}$ under an inverted fluorescence microscope (Olympus Corporation) at x200 magnification and quantification of scratch closure was evaluated using the wound healing measurement tool of ImageJ V1.8.0.112 (National Institutes of Health).

$R T-q P C R$. Total RNA was isolated from MSCs or OBs using TRIzol $^{\circledR}$ reagent (Invitrogen; Thermo Fisher Scientific, Inc.). RT-qPCR was performed as described by Yin et al (25). RT was performed using a PrimeScript ${ }^{\mathrm{TM}}$ RT reagent kit (cat. no. RR047A; Takara Biotechnology Co., Ltd.) and a reaction system was established containing $2.2 \mu \mathrm{g} \mathrm{RNA}, 2.0 \mu \mathrm{l}$ OligodT, $4.0 \mu \mathrm{l}$ dNTP, $4.0 \mu 1$ 5X buffer, $1.0 \mu 1$ reverse transcriptase, $0.5 \mu 1$ RNAase inhibitor and $\leq 20.0 \mu 1$ RNAase-free $\mathrm{ddH}_{2} \mathrm{O}$. The reaction conditions were as follows: $25^{\circ} \mathrm{C}$ for $5 \mathrm{~min}, 50^{\circ} \mathrm{C}$ for $15 \mathrm{~min}, 85^{\circ} \mathrm{C}$ for $5 \mathrm{~min}$ and $4^{\circ} \mathrm{C}$ for $10 \mathrm{~min}$. qPCR was performed using a 2xT5 SYBR Green Fast qPCR Mix kit (cat. no. TSE202; TsingKe Biological Technology) according to the manufacturer's instructions. The reaction system contained 0.4 forward primer, 0.4 reverse primer, 10.0 SYBR Green and $5.2 \mu \mathrm{l} \mathrm{H}_{2} \mathrm{O}$. The thermocycling conditions were as follows: $50^{\circ} \mathrm{C}$ for $2 \mathrm{~min}, 95^{\circ} \mathrm{C}$ for $10 \mathrm{~min}, 95^{\circ} \mathrm{C}$ for $30 \mathrm{sec}$ and $60^{\circ} \mathrm{C}$ for $30 \mathrm{sec}$ for 40 cycles. The $2^{-\Delta \Delta \mathrm{Cq}}$ method was used to calculate the relative expression levels (26). The primers were as follows (5'-3'): BMP2 forward, TGGCCC ATTTAGAGGAGAACC and reverse, AGGCATGATAGC CCGGAGG; RUNX family transcription factor (RunX)2 forward, GAGACTACTGCCGACCAC and reverse, TACCTC TCCGAGGGCTACC; collagen (COL)-1 forward, AGGGCC AAGACGAAGACATC and reverse, AGATCACGTCATCGC ACAACA; osteocalcin (OCN) forward, CTCACACTCCTC GCCCTATT and reverse, CGCCTGGGTCTCTTCACTAC; $\beta 2$-AR forward, GGACAACCTCATCCCTAA and reverse, GGACAACCTCATCCCTAA and GAPDH forward, CAC ATGGCCTCCAAGGAGTAA and reverse, GTACATGAC AAGGTGCGGCTC. GAPDH was used as the control for normalization.

Protein expression level detection by western blot analysis. Western blotting was performed as described by Yin et al (25). Total protein was extracted from MSCs or OBs and bone tissue using RIPA reagent (Beyotime Institute of Biotechnology), and the concentration of extracted proteins was measured by BCA. Proteins (20 $\mu \mathrm{g} /$ lane) were isolated using SDS-PAGE (12\% separating gel and 5\% stacking gel) and transferred to polyvinylidene difluoride membranes. The membranes were blocked with 5\% BSA (Beyotime Institute of Biotechnology) at $37^{\circ} \mathrm{C}$ for $1 \mathrm{~h}$. The membranes were incubated with primary antibodies against BMP2, RunX2, COL-1, OCN and $\beta 2-\mathrm{AR}$ overnight at $4^{\circ} \mathrm{C}$, and using corresponding secondary antibodies incubated for $1.5 \mathrm{~h}$ at room temperature. Protein bands were detected by an enhanced chemiluminescent kit (Thermo Fisher Scientific, Inc.). The antibodies (all Chongqing Boai Madison Biotechnology Co., Ltd.) were as follows: BMP2 (1:500; cat. no. BM19970), RunX2 (1:500; cat. no. BM16360), COL-1 (1:500; cat. no. BM2319), OCN (1:500; cat. no. BM18692), $\beta 2-A R$ (1:500; cat. no. BMP0265), $\beta$-actin $(1: 2,000$; cat. no. BMC026) and horseradish peroxidase-conjugated goat anti-rabbit IgG (1:2,000; cat. no. BMS014). Results were normalized yo $\beta$-actin. Western blots were quantified using Image J V1.8.0.112 (National Institutes of Health).

Immunofluorescence detection. Immunofluorescence detection was performed as described by Fathi et al (18). The MSCs or OBs were fixed with $4 \%$ paraformaldehyde at $4^{\circ} \mathrm{C}$ overnight. Paraffin-embedded sections (thickness, $4 \mu \mathrm{m}$ ) were baked at $60^{\circ} \mathrm{C}$ for $2 \mathrm{~h}$, dewaxed and hydrated with xylene and alcohol. The sections were placed in citrate buffer solution (pH 6.0) for antigen repair, heated at $98^{\circ} \mathrm{C}$ in a microwave oven for $20 \mathrm{~min}$ and left to cool to room temperature. Three cycles of washing were performed with PBS (5 min each) followed 
A
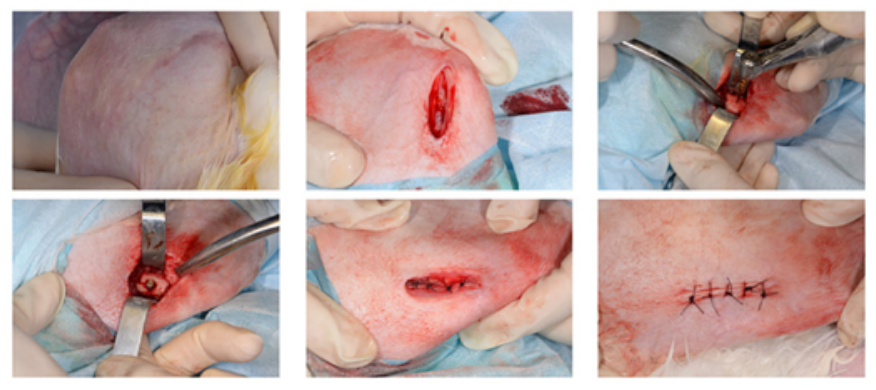

C

BMP2

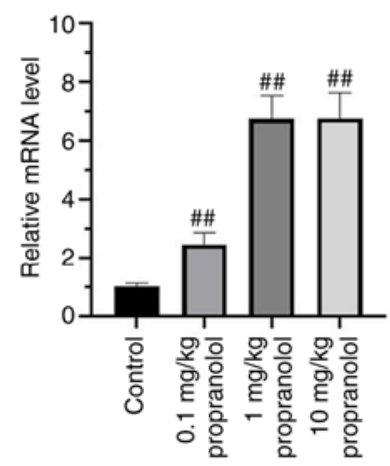

COL-1

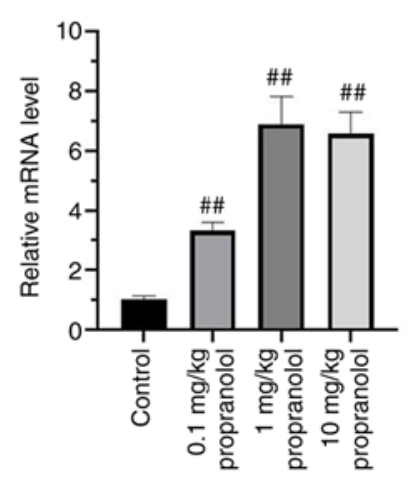

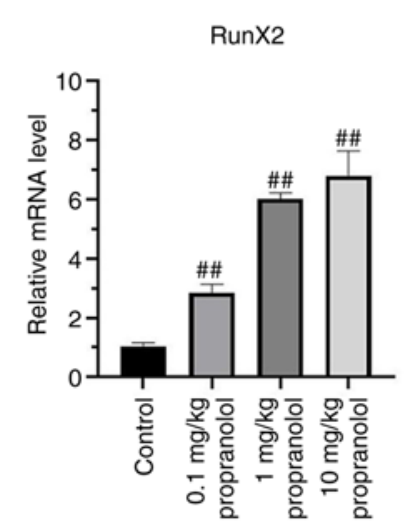

OCN

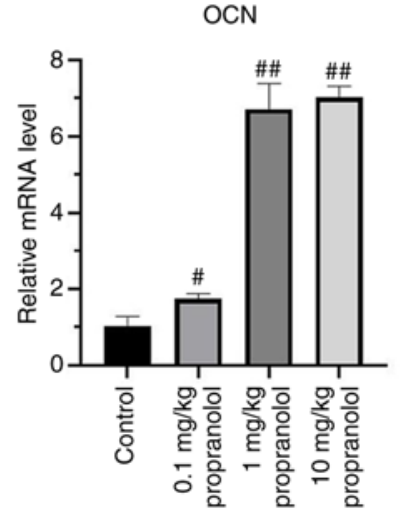

B
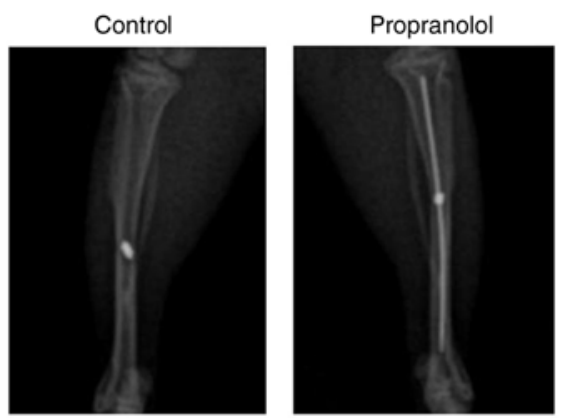

D
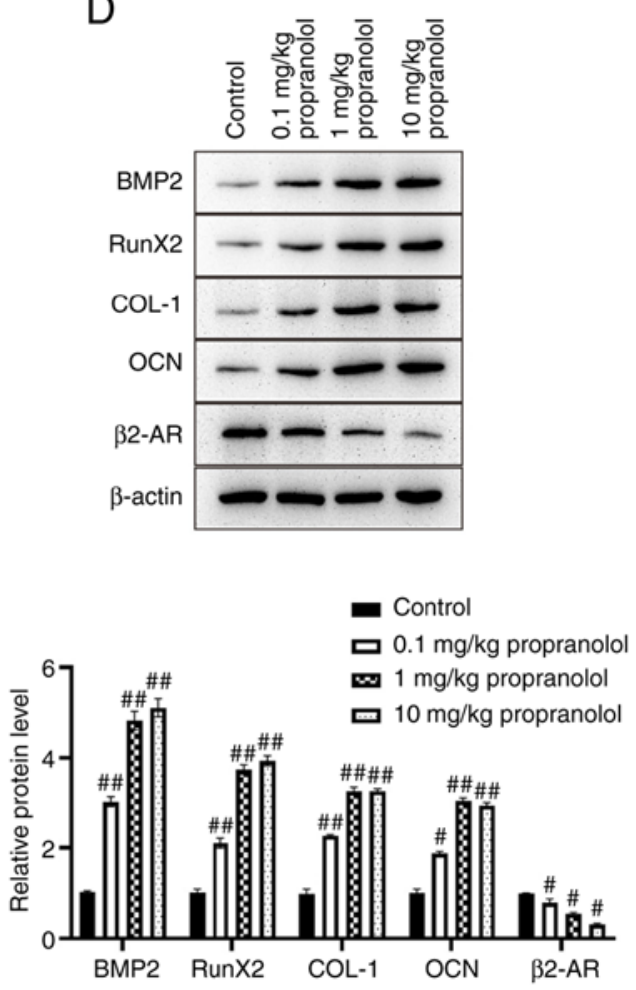

Figure 1. Propranolol promotes osseointegration of implants. (A) Preparation of New Zealand rabbit implant femoral shaft fracture model. (B) X-ray examination of bone binding. Expression of BMP2, RunX2, COL-1 and OCN detected by (C) reverse transcription-quantitative PCR and (D) western blotting. Statistical significance was assessed by ANOVA with Tukey's post hoc test. ${ }^{\#} \mathrm{P}<0.05$, ${ }^{\#} \mathrm{P}<0.01$ vs. control. BMP2, bone morphogenetic protein 2 ; RunX2, RUNX family transcription factor 2; COL-1, collagen 1; OCN, osteocalcin; AR, adrenergic receptor.

by blocking with $5 \%$ BSA for $30 \mathrm{~min}$ at room temperature. The aforementioned primary antibodies (1:100) were added and incubated overnight at $4^{\circ} \mathrm{C}$. Antibodies are described in western blot. Following reheating at $37^{\circ} \mathrm{C}$ for $30 \mathrm{~min}$, PBS was used for washing (3 times; 5 min each). Corresponding secondary antibodies conjugated to Alexa594 (cat. no. R37117, 1:100; Thermo Fisher Scientific, Inc.) were added and incubated at room temperature for $1 \mathrm{~h}$. PBS washing was repeated 3 times ( $5 \mathrm{~min}$ each). Nuclei were visualized by staining with $0.3 \mu \mathrm{M}$ DAPI in the dark for $5-10 \mathrm{~min}$ at $37^{\circ} \mathrm{C}$ and then PBS was used to wash 3 times (1 min each). The sections were observed and photographed under a fluorescence microscope at x200 magnification.

Statistical analysis. The experimental data were statistically analyzed using SPSS 23.0 software (IBM Corp.) and are expressed as the mean \pm SD of three independent experiments. A paired t-test was used to compare groups before and after treatment. One-way ANOVA with Tukey's post hoc test was used for comparison between multiple groups. $\mathrm{P}<0.05$ and $\mathrm{P}<0.01$ were considered to indicate a statistically significant difference.

\section{Results}

Propranolol promotes osseointegration of implants. A New Zealand white rabbit model of implant osseointegration was established and injected with different doses of propranolol $(0.1,1.0$ and $10.0 \mathrm{mg} / \mathrm{kg})$. At 14 days post-surgery, bone tissue binding to implants and absorption were examined by X-ray scanning (Fig. 1A and B). Bone tissue samples of rabbits near the implants were collected and mRNA expression of BMP2, 
A
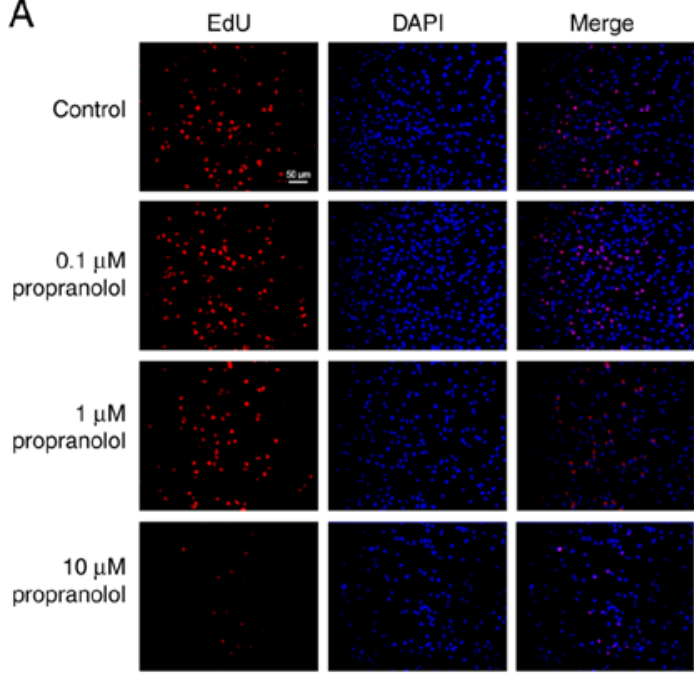

$\mathrm{B}$
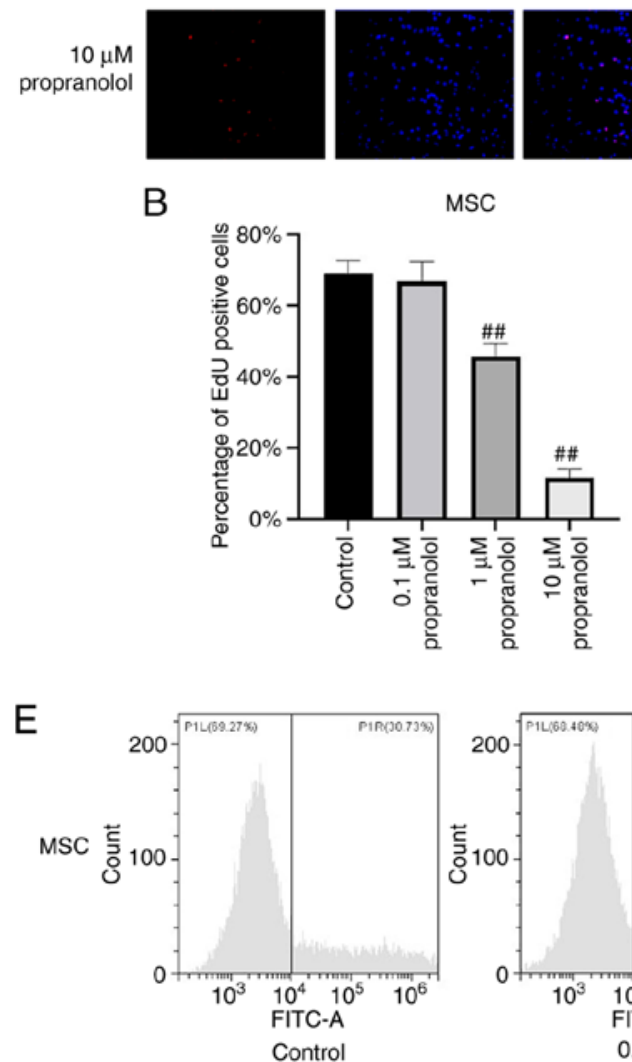

$\mathrm{F}$

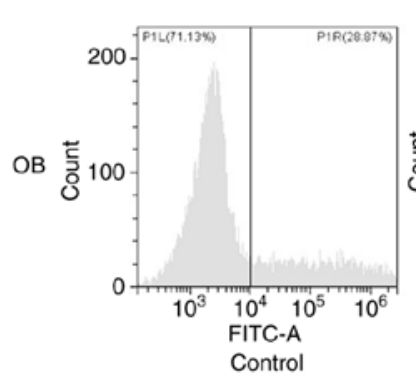

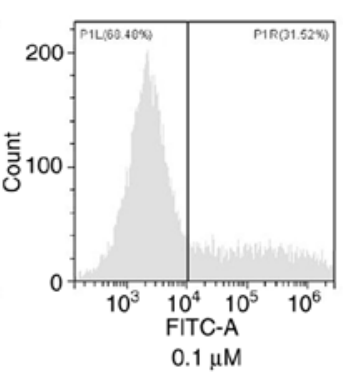
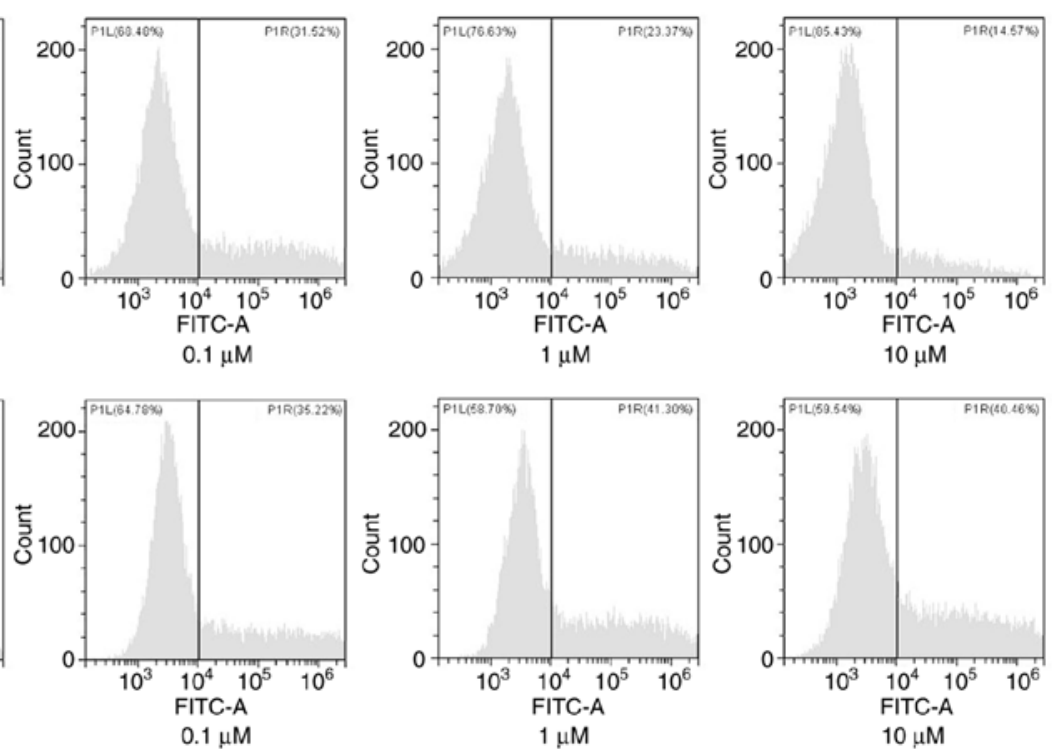

Figure 2. Propranolol inhibits proliferation of MSCs and promotes proliferation of OBs. (A) Effect of propranolol on MSCs proliferation was determined by EdU staining. Magnification, x200. Scale bar, $50 \mu \mathrm{m}$. (B) Statistical analysis of EDU positive cells in MSCs. (C) Effect of propranolol on OBs proliferation was determined by EdU staining. (D) Statistical analysis of EDU positive cells in OBs. (E) Proliferation rate of MSCs was determined by flow cytometry. (F) Proliferation rate of OBs was determined by flow cytometry. Statistical significance was assessed by ANOVA with Tukey's post hoc test. ${ }^{\# \#} \mathrm{P}<0.01$ vs. control. MSC, mesenchymal stem cell; OB, osteoblast.

RunX2, COL-1, OCN, and $\beta 2-\mathrm{AR}$ was detected by qPCR. Propranolol increased mRNA expressions of BMP2, RunX2, COL- 1 and OCN and decreased that of $\beta 2-\mathrm{AR}$. The protein expression of BMP2, RunX2, COL-1, OCN and $\beta 2-\mathrm{AR}$ was detected by western blotting; propranolol increased protein levels of BMP2, RunX2, COL-1 and OCN and decreased $\beta 2$-AR levels. (Fig. $1 \mathrm{C}$ and D).

Propranolol inhibits proliferation of MSCs and promotes proliferation of OBs. To determine the effect of propranolol on 

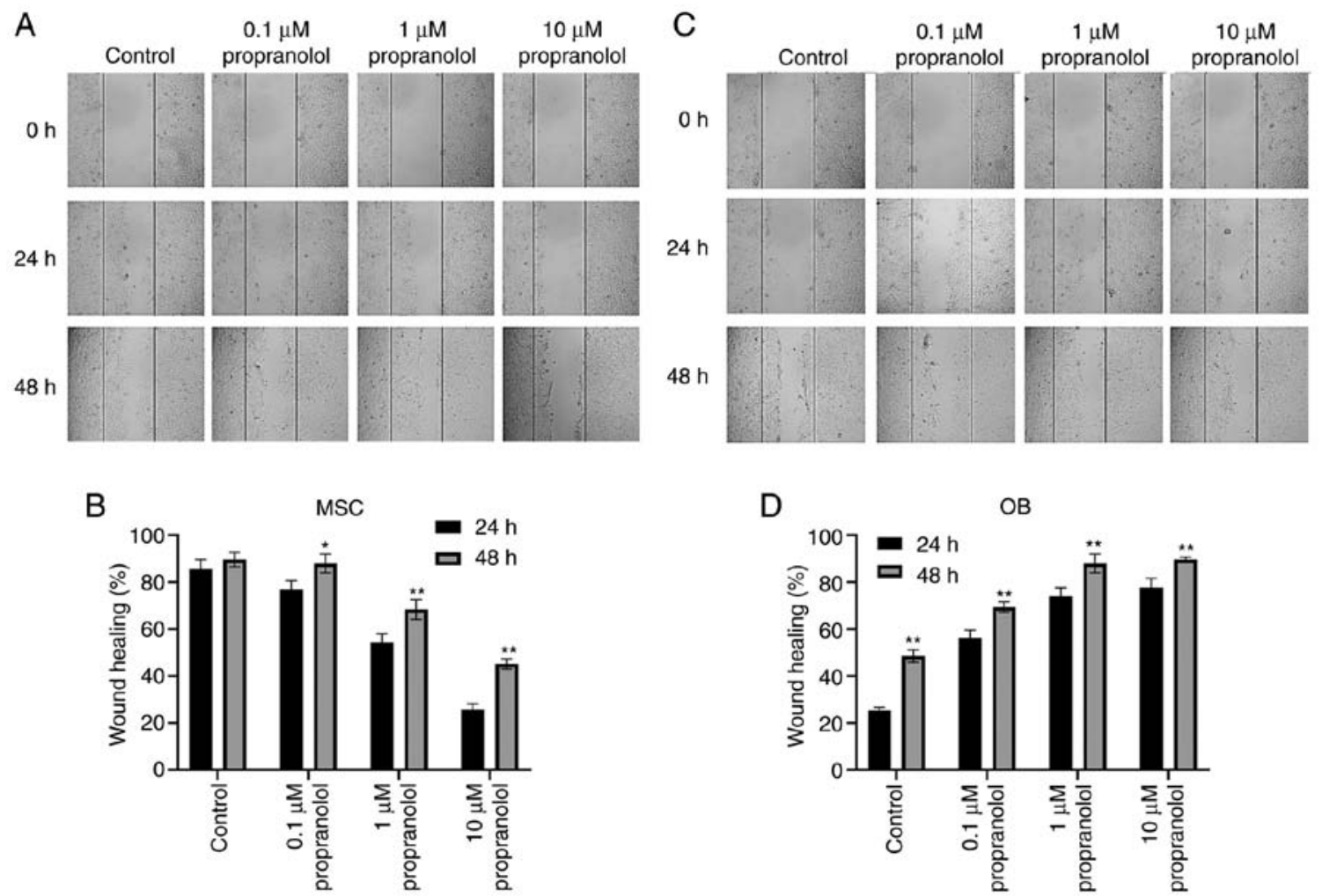

Figure 3. Propranolol inhibits migration of MSCs and promotes migration of OBs. Wound healing assay assessed MSC migration efficiency of (A and B) MSCs and $(C$ and $D)$ OBs following treatment with propranolol. Images were captured at 0,24 , and $48 \mathrm{~h}$ (x200 magnification). Statistical significance was assessed by Student's $t$-test. ${ }^{*} \mathrm{P}<0.05,{ }^{* *} \mathrm{P}<0.01$ vs. $24 \mathrm{~h}$. MSC, mesenchymal stem cell; OB, osteoblast.

A

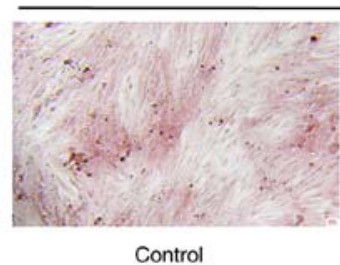

Control

MSC

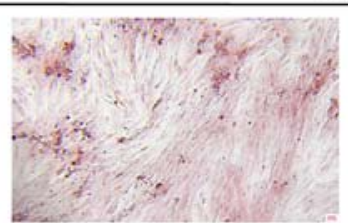

$0.1 \mu \mathrm{M}$ propranolol

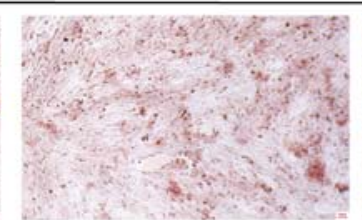

$1 \mu \mathrm{M}$ propranolol

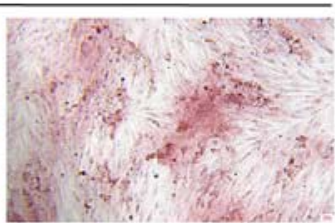

$10 \mu \mathrm{M}$ propranolol

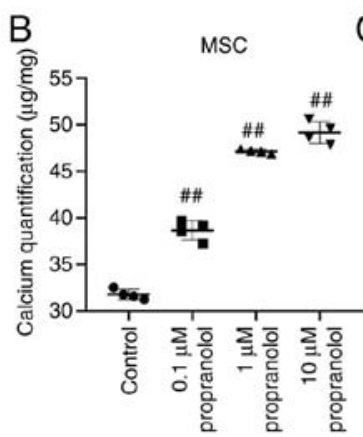

C
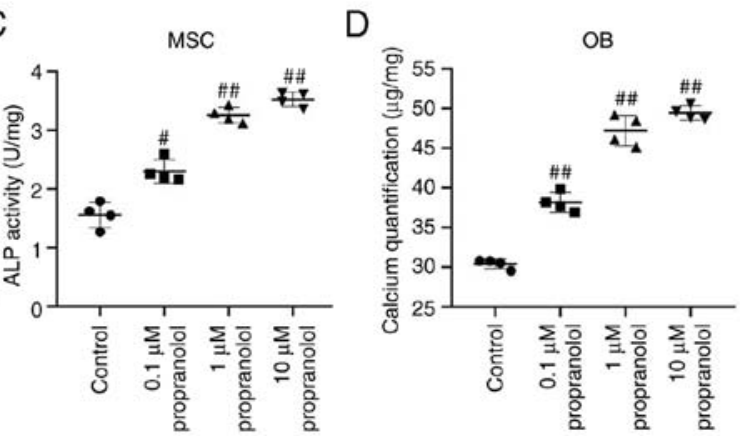

E

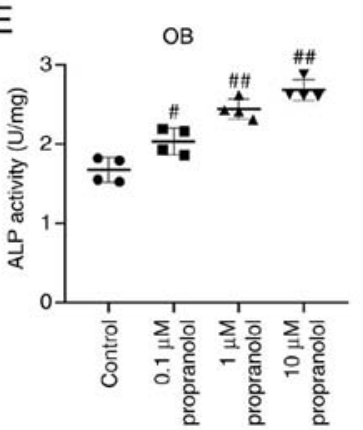

F

OB

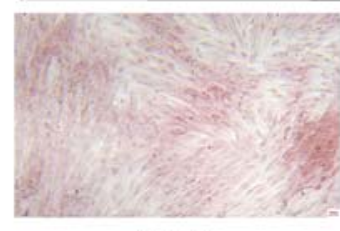

Control

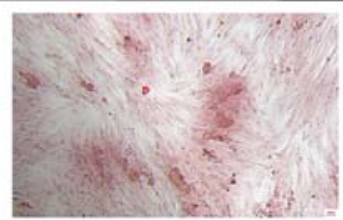

$0.1 \mu \mathrm{M}$ propranolol

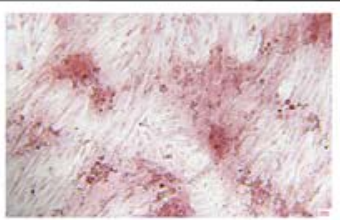

$1 \mu \mathrm{M}$ propranolol

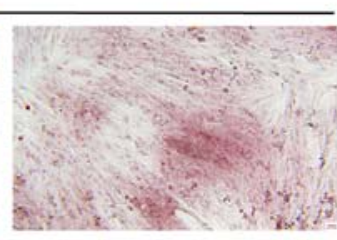

$10 \mu \mathrm{M}$ propranolol

Figure 4. Propranolol promotes osteogenic differentiation of MSCs and OBs. (A) Alizarin red staining detected the osteogenic differentiation of MSCs. Determination of (B) calcium content and (C) ALP activity in MSCs. Determination of (D) calcium and (E) ALP activity in OBs. (F) Determination of osteogenic differentiation of $\mathrm{OB}$ by alizarin red staining. Statistical significance was assessed by ANOVA with Tukey's post hoc test. "P $<0.05$, ${ }^{\# \#} \mathrm{P}<0.01$ vs. control. MSC, mesenchymal stem cell; OB, osteoblast; ALP, alkaline phosphatase. 
A

BMP2
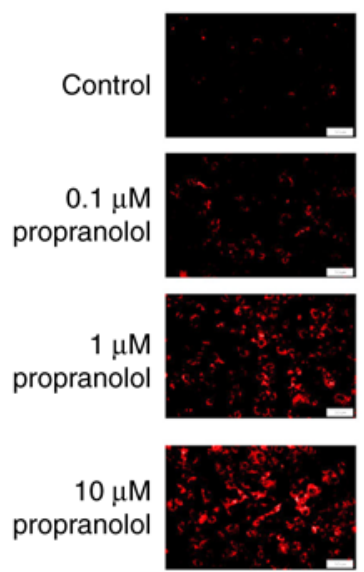

C
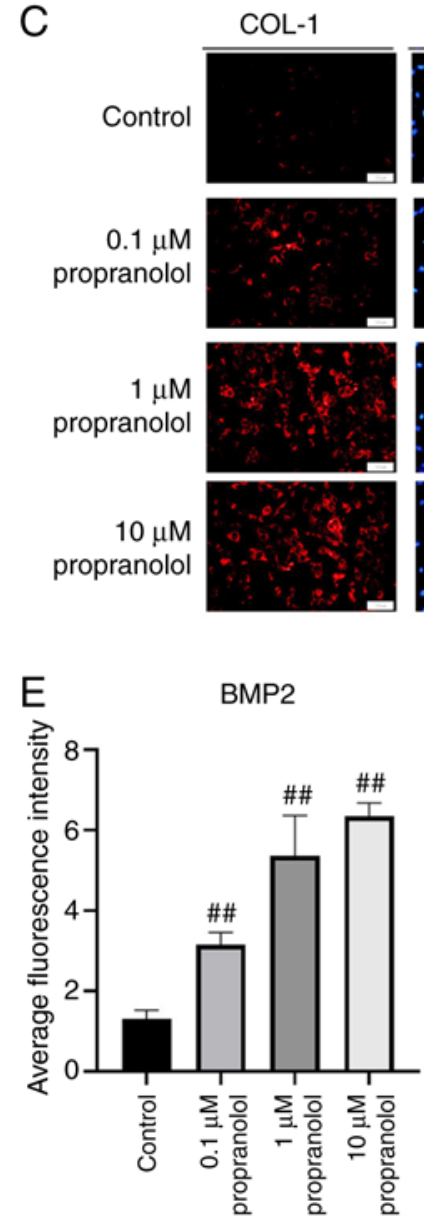

DAPI
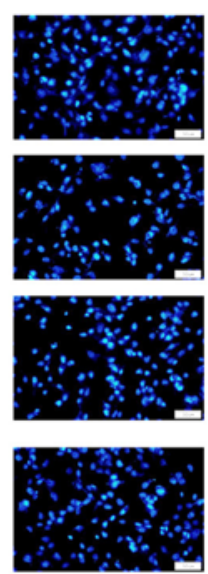

\section{DAPI}
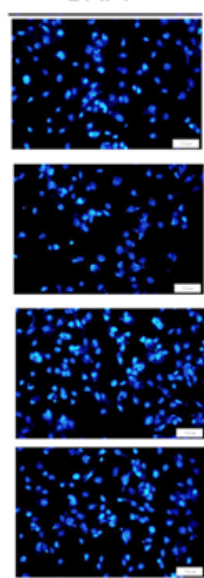

F
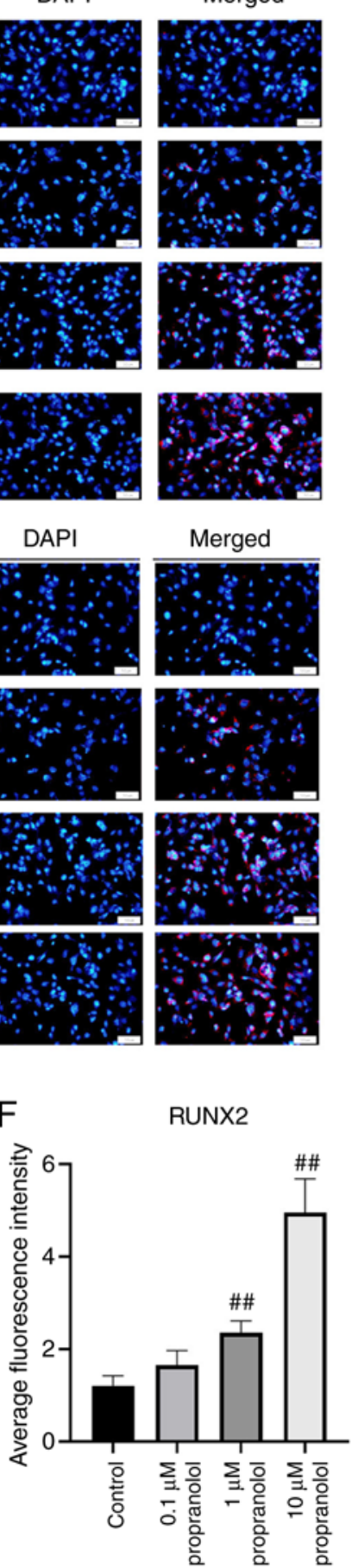

Merged
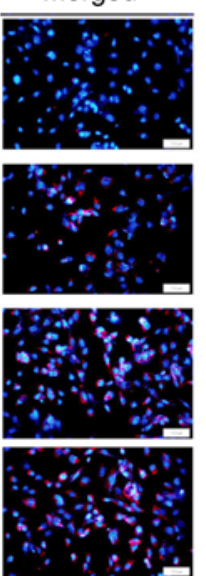

B

G
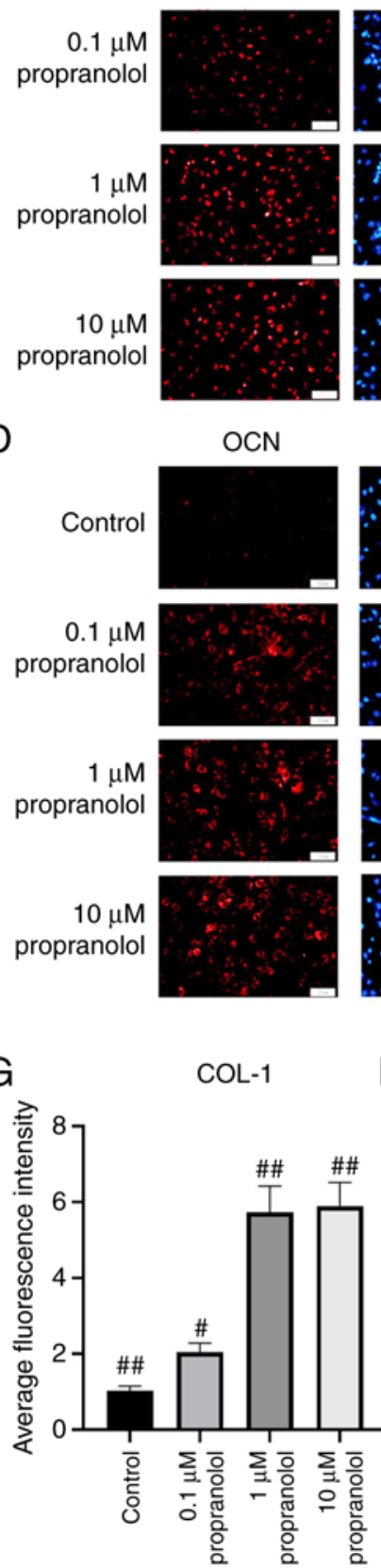

D
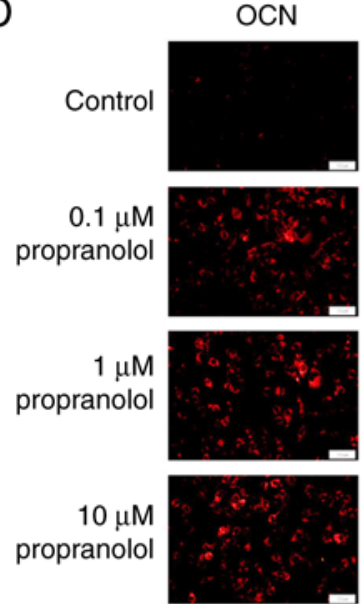
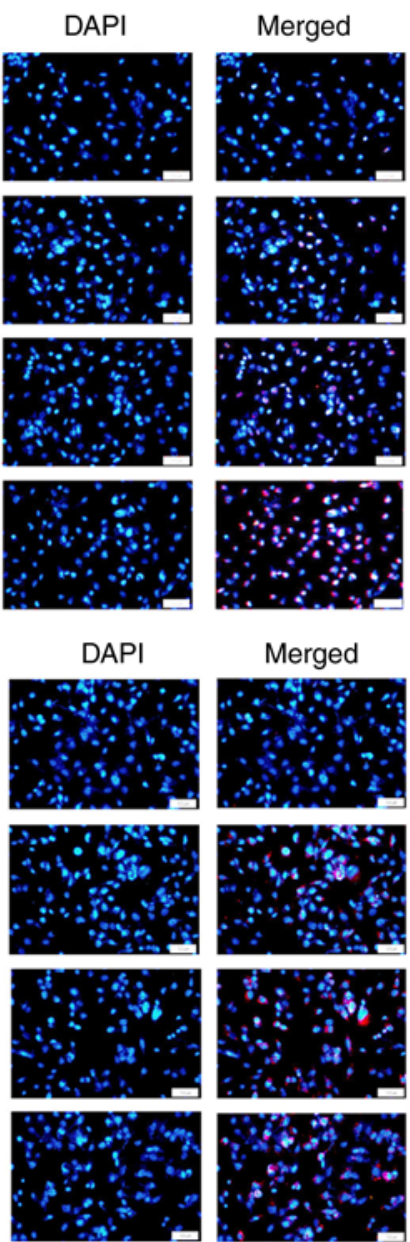

$\mathrm{H}$

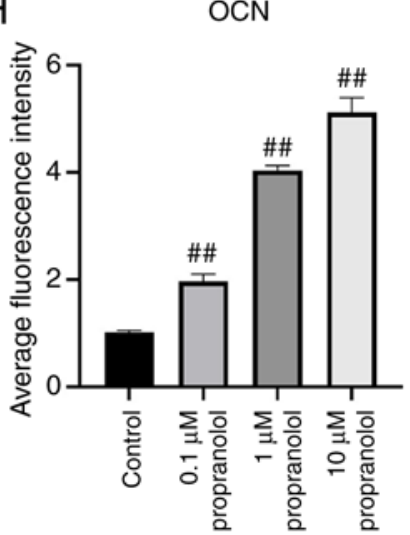

Figure 5. Regulatory effect of propranolol on osteogenesis-associated genes in MSCs. Immunofluorescence was used to detect (A) BMP2, (B) RunX2, (C) COL-1 and (D) OCN expression levels in MSCs. Relative immunofluorescence intensity of (E) BMP2, (F) RunX2, (G) COL-1 and (H) OCN was measured by Image J. Magnification, x200. Scale bar, $50 \mu \mathrm{m}$. Statistical significance was assessed by ANOVA with Tukey's post hoc test. ${ }^{\# P}<0.05$, ${ }^{\# \#} \mathrm{P}<0.01$. BMP2, bone morphogenetic protein 2; RunX2, RUNX family transcription factor 2; COL-1, collagen 1; OCN, osteocalcin; MSC, mesenchymal stem cell; OB, osteoblast.

proliferation of MSCs and OBs, MSCs and OBs were cultured in vitro using complete medium containing isoproterenol and treated with propranolol for $24 \mathrm{~h}$. Cell proliferation was detected by EdU staining. The number of EdU-positive MSCs decreased markedly following the addition of propranolol and was lowest in the $10 \mu \mathrm{M}$ propranolol group, indicating that propranolol inhibited proliferation of MSCs (Fig. 2A and B). In OBs, all concentrations of propranolol significantly promoted cell proliferation and the number of Edu-positive cells in the
1 and $10 \mu \mathrm{M}$ propranolol groups were similar (Fig. 2C and D). These results suggested that propranolol inhibited proliferation of MSCs and promoted proliferation of OBs.

Propranolol inhibits migration of MSCs and promotes migration of OBs. The effect of propranolol on cell migration was detected by wound healing at 24 and $48 \mathrm{~h}$. MSC migration was inhibited following the addition of propranolol to complete medium containing isoproterenol. Moreover, the healing rate 
A

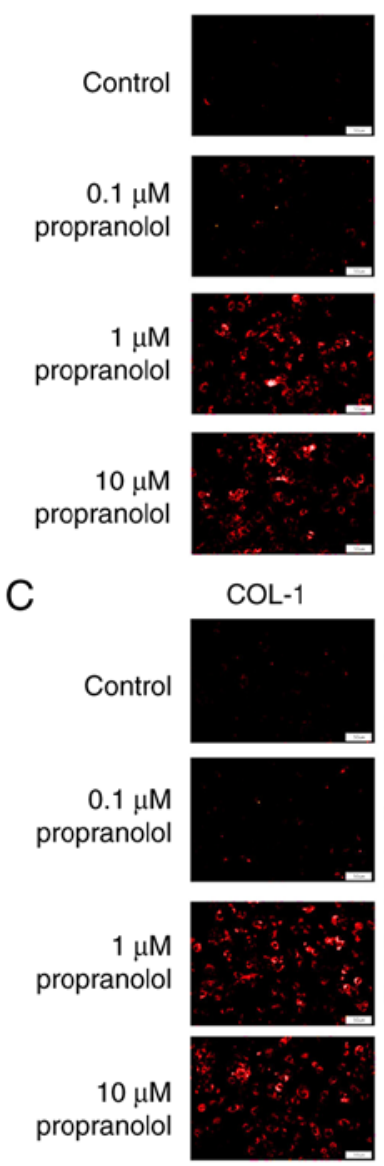

$\mathrm{E}$

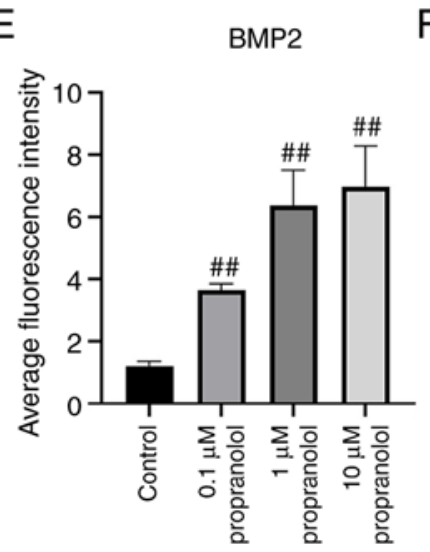

DAPI
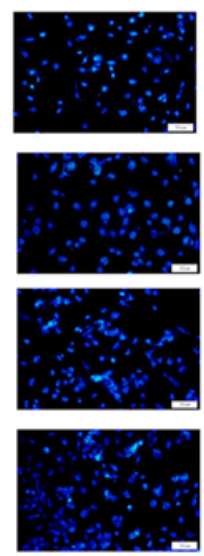

DAPI
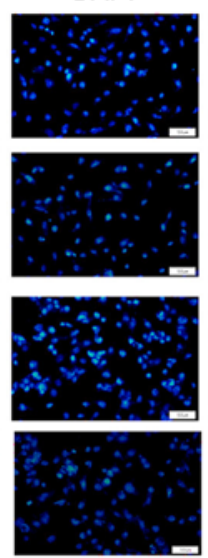

$\mathrm{F}$

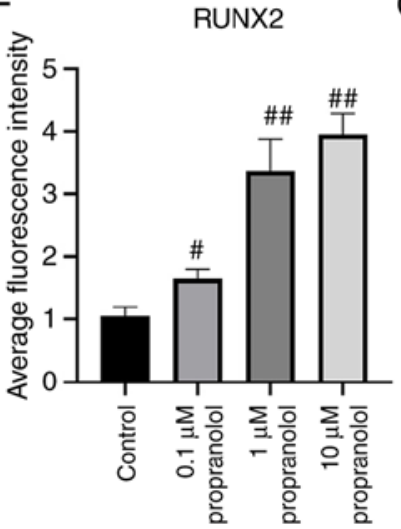

Merged
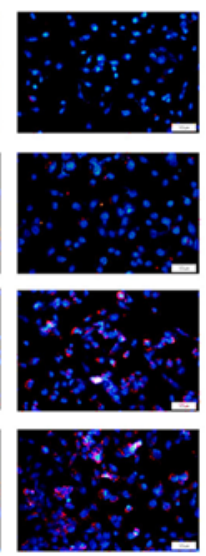

Merged
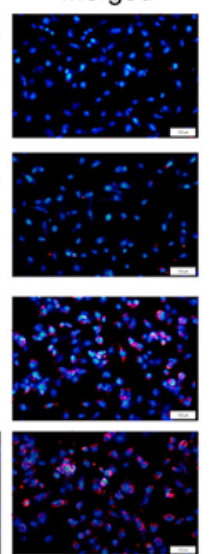

$10 \mu \mathrm{M}$
propranolo

G
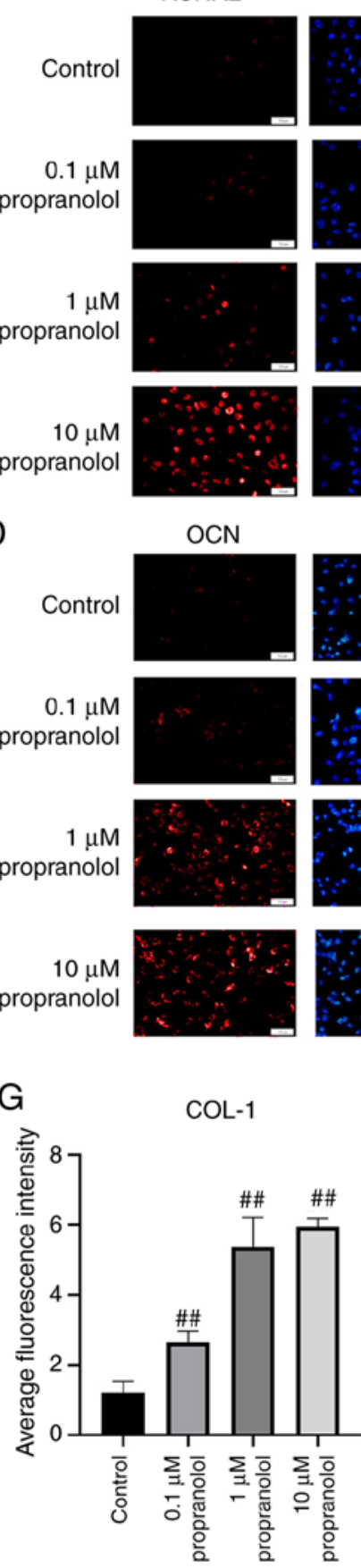

$10 \mu \mathrm{M}$ propranolol

D
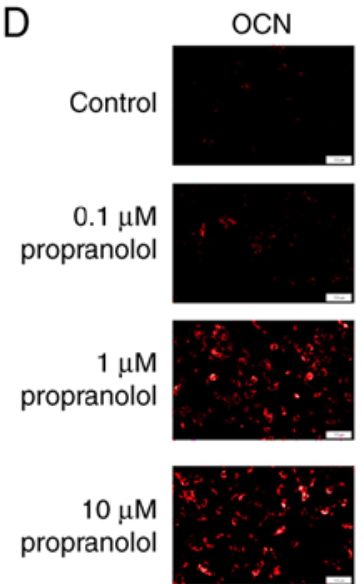

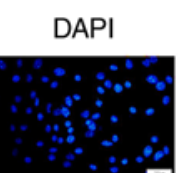

Merged
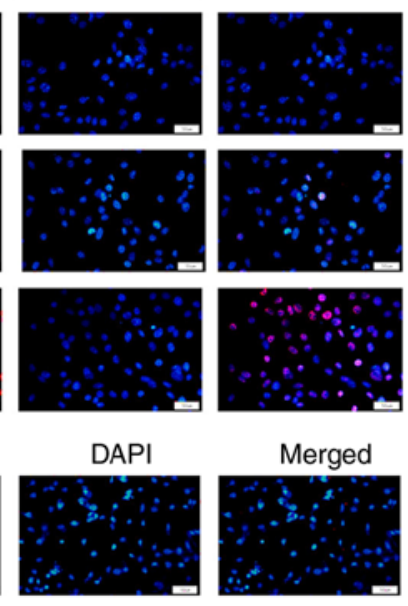

Merged
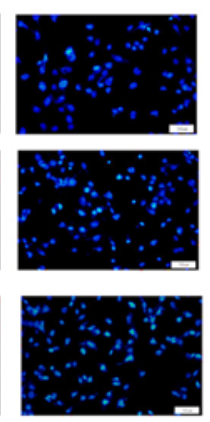

$\mathrm{H}$

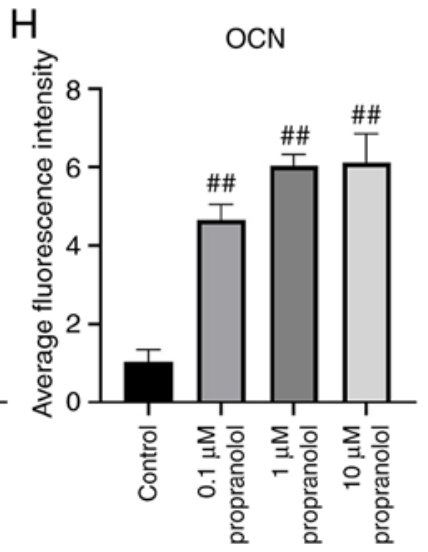

Figure 6. Regulatory effect of propranolol on osteogenesis-associated genes in OBs. Immunofluorescence was used to detect (A) BMP2, (B) RunX2, (C) COL-1 and (D) OCN expression in OBs. Relative immunofluorescence intensity of (E) BMP2, (F) RunX2, (G) COL-1 and (H) OCN was measured by Image J. Magnification, $\mathrm{x} 200$. Scale bar, $50 \mu \mathrm{m}$. Statistical significance was assessed by ANOVA with Tukey's post hoc test. ${ }^{\# P}<0.05$, ${ }^{\#} \mathrm{P}<0.01$, vs. control. BMP2, bone morphogenetic protein 2; RunX2, RUNX family transcription factor 2; COL-1, collagen 1; OCN, osteocalcin; MSC, mesenchymal stem cell; OB, osteoblast.

of scratches was markedly lower in propranolol-treated MSCs compared with the control group; the higher the concentration, the lower the healing rate (Fig. 3A and B). Conversely, propranolol improved the healing rate of OBs and cell migration was higher than that of the control group (Fig. 3C and D). These results suggested that propranolol inhibited MSC migration and promoted OB migration.

Propranolol promotes osteogenic differentiation of MSCs and $O B s$. To determine the effect of propranolol on osteogenic differentiation of MSCs and OBs, MSCs and OBs cultured in vitro with osteogenic differentiation medium containing isoproterenol and propanolol. Following induction for 7 days, osteogenic differentiation of cells was detected by alizarin red staining. Propranolol promoted osteogenic differentiation of both MSCs and OBs and increased the number of intracellular calcium nodules following induction. The calcium content and ALP activity of cells treated with propranolol were significantly higher compared with the control group (Fig. 4A-F).

Regulatory effect of propranolol on osteogenesis-associated genes. To elucidate the osteogenic mechanism of propranolol in 
A
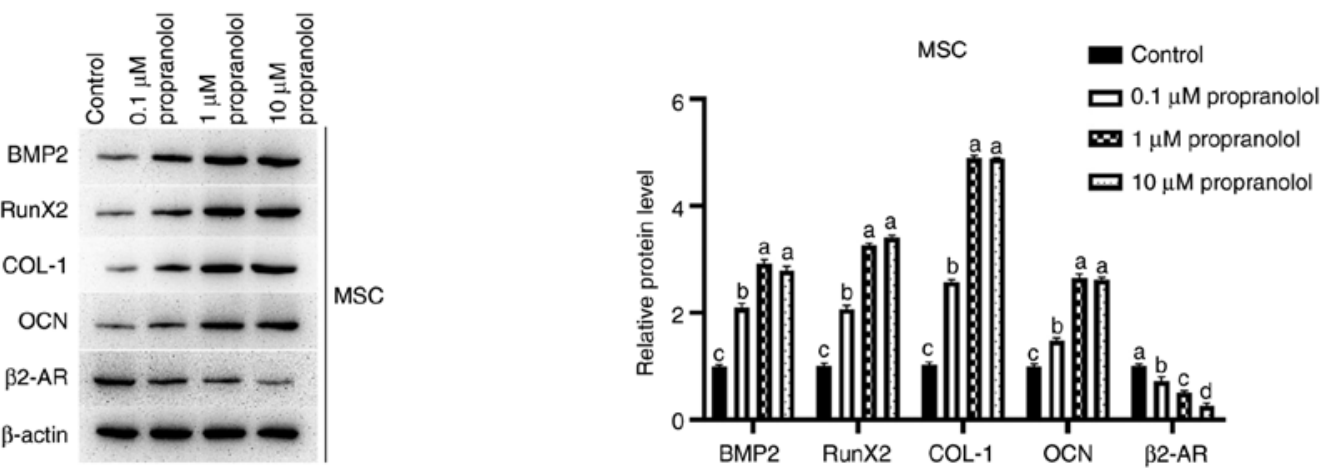

B
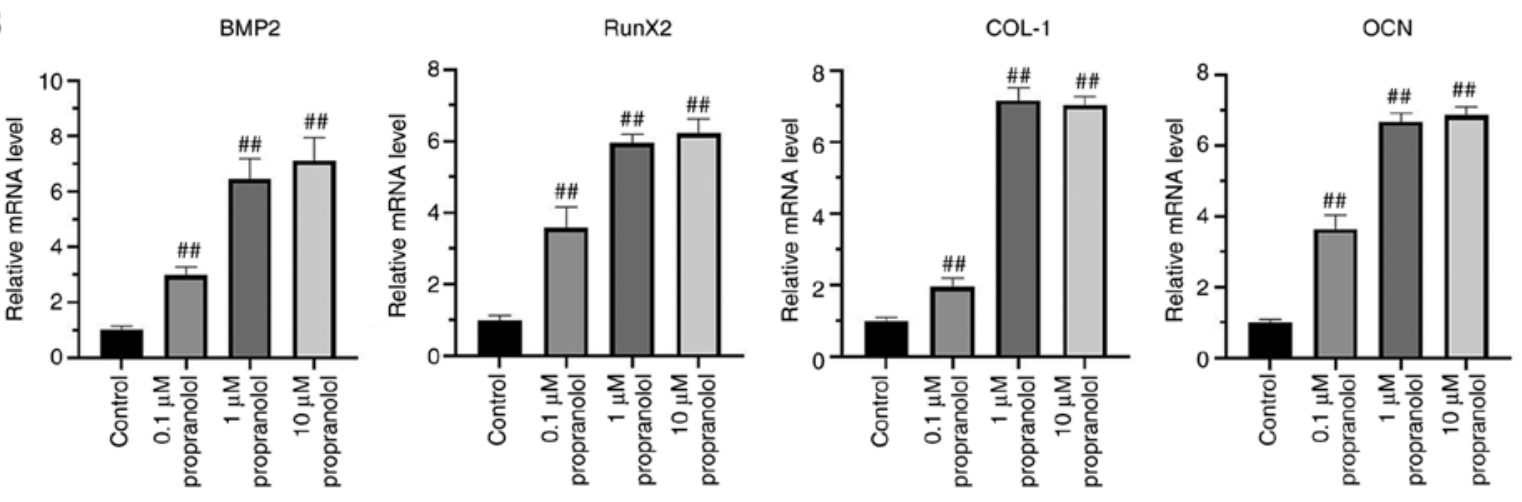

MSC
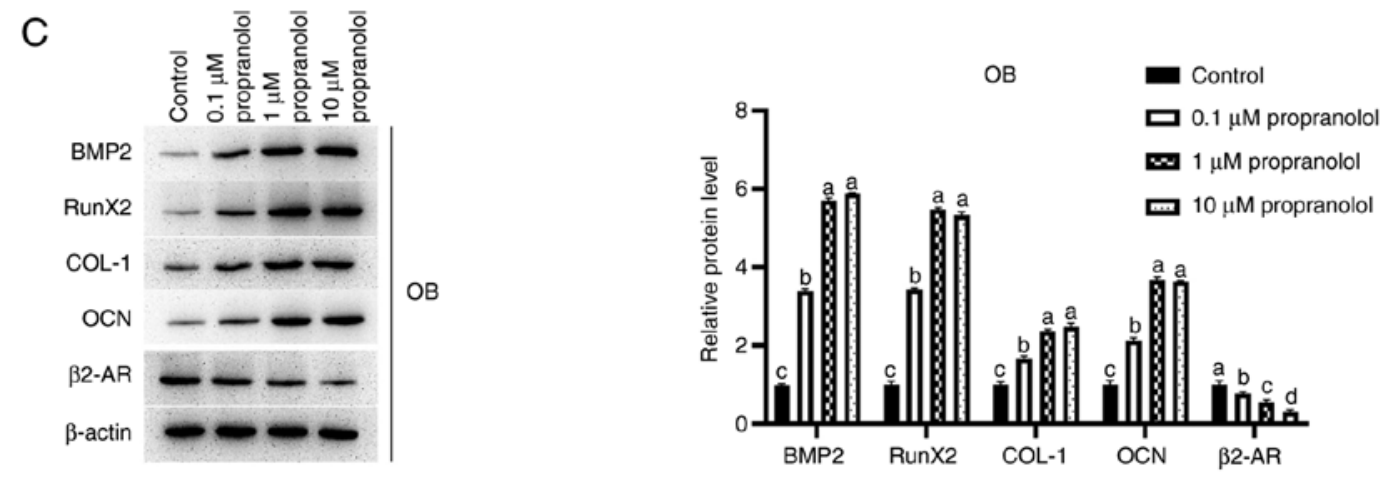

D
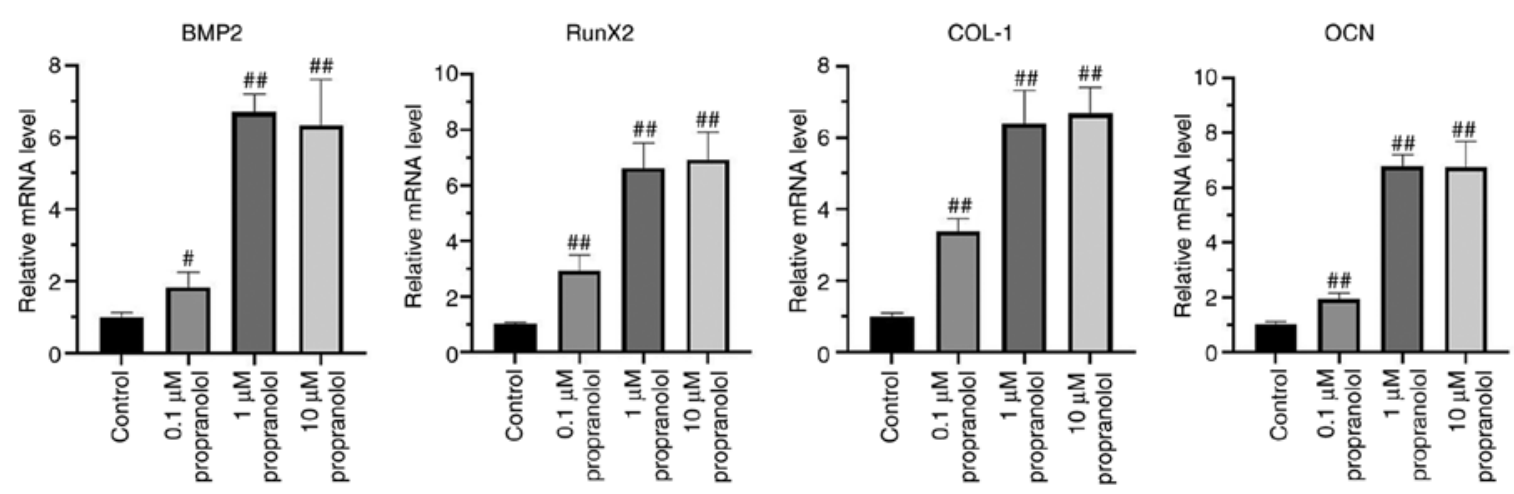

$\mathrm{OB}$

Figure 7. Expression levels of BMP2, RunX2, COL-1, OCN and $\beta 2$-AR in MSCs and OBs detected by RT-qPCR and western blotting. Expression levels of BMP2, RunX2, COL-1, OCN and $\beta 2$-AR in MSC were detected by (A) western blotting and (B) RT-qPCR. Expression levels of BMP2, RunX2, COL-1, OCN and $\beta 2$-AR in OB were detected by (C) western blotting and (D) RT-qPCR. Statistical significance was assessed by ANOVA with Tukey's test. ${ }^{\# P}<0.05$, ${ }^{\# \prime} \mathrm{P}<0.01$ vs. control. BMP2, bone morphogenetic protein 2; RunX2, RUNX family transcription factor 2; COL-1, collagen 1; OCN, osteocalcin; MSC, mesenchymal stem cell; OB, osteoblast; AR, adrenergic receptor; RT-q, reverse transcription-quantitative.

regulating MSCs (Fig. 5A-H) and OBs (Fig. 6A-H), expression levels of osteogenesis-associated genes BMP2, RunX2,COL-1,
OCN and $\beta 2-\mathrm{AR}$ were detected by immunofluorescence, RT-qPCR and western blotting. The findings demonstrated 
that propranolol significantly increased protein expression levels of BMP2, RunX2, COL-1 and OCN and decreased expression of $\beta 2-\mathrm{AR}$ in a dose-dependent manner. The results of RT-qPCR and western blotting were consistent with those of immunofluorescence analysis, indicating that propranolol upregulated expression levels of osteogenesis-associated genes (BMP2, RunX2, COL-1 and OCN), thereby promoting osteogenic differentiation of MSCs and OBs (Fig. 7A-D).

\section{Discussion}

Early rapid osseointegration is a key factor for successful implantation but is limited by biological inertia, high elastic modulus and limited biological effects of the material surface (27). An effective technique to improve the performance of titanium implants and to promote and accelerate osseointegration has been the focus of research in recent years (28-30). Despite titanium and titanium alloy implants are widely used in the fields of dentistry and oral and maxillofacial surgery, postoperative infection and poor osseointegration remain obstacles to implant surgery (31). Drugs, such as zoledronic acid, osteoprotegerin, and kaempferol, also promote early osseointegration of implants (32-34).

As an integrated part of the autonomic nervous system of the human body, the sympathetic nervous system serves a key role in regulating homeostasis. Growing evidence has shown that the sympathetic nervous system is involved in bone remodeling (6,35). In 1977, Duncan and Shim (36) demonstrated that the surface of intraosseous vessels is covered with rich adrenergic nerve fibers by observing the bone tissue of rabbits using histochemistry and fluorescence electron microscopy. Mach et al (37) demonstrated that sympathetic nerve fibers are primarily located in the bone marrow cavity, favors areas of abundant blood flow and are rare in the periosteum. When the sympathetic nerve is excited, bone resorption is promoted and bone formation is decreased via $\beta 2$-ARs on the surface of OBs (38). $\beta 2$-AR has been visualized on the surface of human OBs by immunofluorescence and studies using $\beta 2-\mathrm{AR}$ agonists indicated that they serve a role in inhibiting proliferation of OBs $(38,39)$. Although regulation of sympathetic nerve on bone turnover via $\beta 2$-ARs expressed on OBs has been demonstrated, little is known about the effect of $\beta$-AR blocker propranolol on osteogenic differentiation of OBs. In the study, propranolol promoted the proliferation and differentiation of OBs, which is consistent with previous studies $(40,41)$.

Propranolol is a recognized drug for treatment of hypertension and cardiovascular disease (42-44). Propranolol is a non-selective $\beta 1$ and $\beta 2$-AR blocker that has been used since 1964 to treat coronary artery insufficiency (45). Propranolol competitively inhibits the action of epinephrine and norepinephrine on $\beta 1$ - and $\beta 2$-ARs (46). Multiple studies have shown that propranolol inhibits expression of $\beta 2$-AR $(47,48)$. Previously, the effect of propranolol on bone metabolism has received attention $(41,49,50)$. Minkowitz et al (49) reported that mineral deposition and bone formation increase in a rat model of surgical fracture treated with propranolol for 9 weeks. Bonnet et al (41) found that low-dose propranolol improved bone formation and prevented osteoclasts proliferation in ovariectomized rats. Epidemiological studies have also demonstrated that $\beta 2$-AR blockers serve as potential candidate drugs for treatment of osteoporosis and fractures $(51,52)$. $\beta$-blockers enhanced bone healing and improved bone metabolism (53). The present study investigated the effects of $\beta$-AR blocker propranolol on osteogenesis in an animal model. The results demonstrated that propranolol promoted osseointegration of implants in rabbits, which is consistent with conclusions of previous studies $(7,50)$, suggesting that propranolol enhances bone regeneration and implant osseointegration.

No consensus on the mechanism of $\beta 2-A R$ in regulating osteogenesis and osteoclast has been reached. By investigating the osteogenic mechanism of MSCs, certain scholars have reported that $\beta$-AR activators inhibit osteogenesis of MSCs, while blockers promote osteogenesis of MSCs $(54,55)$. The $\beta$-AR activator also inhibits the signaling pathway associated with osteogenesis by regulating expression of MEK and ERK1/2 phosphorylation, thereby inhibiting differentiation of BMSCs into osteoblast-like cells in vitro $(56,57)$. The osteogenic capacity of MSCs has been established (58). MSCs serve as a source of osteochondral progenitors that invade bone sites, proliferate and differentiate into cartilage and bones (59). $\beta$-AR antagonists promote MSC osteogenesis $(50,55)$. In the present study, propranolol promoted osteogenic differentiation of MSCs while inhibiting their proliferation. This may be due to inhibition of MSC proliferation during differentiation; this has been reported in previous studies, which illustrated that stem cell differentiation is inhibited but proliferation is promoted $(60,61)$. Osteoblastic differentiation of cells is accompanied by upregulation of osteoblast marker genes, including BMP2, RunX2, COL-1 and OCN $(62,63)$. The present study demonstrated that propranolol increased the mRNA and protein expression levels of BMP2, RunX2, COL-1 and OCN in tissue and cells and decreased expression of $\beta 2-\mathrm{AR}$ in OBs and MSCs. The increased calcium content and ALP activity in propranolol-treated OBs and MSCs also indicated osteoblastic differentiation of cells. The findings provide a basis for further studies on the mechanisms underlying the regulatory effects of propranolol.

There effects and mechanisms of propranolol on osteogenesis at different concentrations are disputed (64). Smitham et al (2014) (65) demonstrated that low-dose propranolol $(0.1 \mathrm{mg} / \mathrm{kg})$ has little effect on bone defect healing, while Bonnet et al (2008) (41) suggested that high-dose propranolol $(10-100 \mathrm{mg} / \mathrm{kg})$ produces no additional positive effect on osteogenesis compared with low-dose propranolol. The present study demonstrated that the osteogenic effect of propranolol at medium $(1 \mathrm{mg} / \mathrm{kg})$ and high $(10 \mathrm{mg} / \mathrm{kg})$ doses was markedly enhanced compared with the low dose $(0.1 \mathrm{mg} / \mathrm{kg})$, whereas no superior effect was revealed in the high- compared with the medium-dose group. However, further investigation of the clinical use of propanolol in this context is required.

The present study demonstrated that the $\beta$-AR blocker propranolol promoted osteogenic differentiation of OBs and MSCs and enhanced osseointegration of implants by regulating expression levels of osteogenic-associated proteins, including BMP2, RunX2, COL-1, OCN and $\beta 2-A R$. The present study therefore provided a novel insight into the application and regulatory mechanisms of propranolol.

\section{Acknowledgements}

Not applicable. 


\section{Funding}

The present study was supported by Open Project (grant no. 2017KB03) from State Key Laboratory of Military Stomatology, the Project QDFY + X2021002 and Project QDFY + X2021004 from the Affiliated Hospital of Qingdao University.

\section{Availability of data and materials}

All data generated or analyzed during this study are included in this published article.

\section{Authors' contributions}

All authors contributed to study conception and design. YW wrote the manuscript. YW, QZ, BZ and XW performed experiments and collected and analyzed data. YW and XW reviewed and edited the manuscript. YW and XW confirm the authenticity of all the raw data. All authors read and approved the final manuscript.

\section{Ethics approval and consent to participate}

The present study was approved by the institutional ethical review committee of the Ethics Committee of The Affiliated Hospital of Qingdao University (approval no. 201905036).

\section{Patient consent for publication}

Not applicable.

\section{Competing interests}

The authors declare that they have no competing interests.

\section{References}

1. Yamakawa D, Kawase-Koga Y, Fujii Y, Kanno Y, Sato M, Ohba S, Kitaura Y, Kashiwagi M and Chikazu D: Effects of helioxanthin derivative-treated human dental pulp stem cells on fracture healing. Int J Mol Sci 21: 9158, 2020.

2. Warzecha J, Seebach C, Flinspach A, Wenger F, Henrich D and Marzi I: Effect of sonic hedgehog/ $\beta$-TCP composites on bone healing within the critical-sized rat femoral defect. Exp Ther Med 5: 1035-1039, 2013.

3. Xu J, Hu X, Jiang S, Wang Y, Parungao R, Zheng S, Nie Y, Liu T and Song K: The application of multi-walled carbon nanotubes in bone tissue repair hybrid scaffolds and the effect on cell growth in vitro. Polymers (Basel) 11: 230, 2019.

4. Banfi G, Lombardi G, Colombini A and Lippi G: Bone metabolism markers in sports medicine. Sports Med 40: 697-714, 2010.

5. Leffers D and Collins L: An overview of the use of bone scintigraphy in sports medicine. Sports Med Arthrosc Rev 17: 21-24, 2009.

6. Niedermair T, Straub RH, Brochhausen C and Grässel S Impact of the sensory and sympathetic nervous system on fracture healing in ovariectomized mice. Int J Mol Sci 21: 21-24, 2020.

7. Tomlinson RE, Christiansen BA, Giannone AA and Genetos DC: The role of nerves in skeletal development, adaptation, and aging. Front Endocrinol (Lausanne) 11: 646, 2020.

8. Farahzadi R, Mesbah-Namin SA, Zarghami N and Fathi E: L-carnitine effectively Induces hTERT gene expression of human adipose tissue-derived mesenchymal stem cells obtained from the aged subjects. Int J Stem Cells 9: 107-114, 2016.
9. Farahzadi R, Fathi E and Vietor I: Mesenchymal stem cells could be considered as a candidate for further studies in cell-based therapy of alzheimer's disease via targeting the signaling pathways. ACS Chem Neurosci 11: 1424-1435, 2020.

10. Li X, Zheng Y, Hou L, Zhou Z, Huang Y, Zhang Y, Jia L and Li W: Exosomes derived from maxillary BMSCs enhanced the osteogenesis in iliac BMSCs. Oral Dis 26: 131-144, 2020

11. Yu L, Wu Y, Liu J, Li B, Ma B, Li Y, Huang Z, He Y, Wang H, $\mathrm{Wu} \mathrm{Z}$ and Qiu G: 3D culture of bone marrow-derived mesenchymal stem cells (BMSCs) could improve bone regeneration in 3D-printed porous Ti6Al4V scaffolds. Stem Cells Int 2018: 2074021,2018

12. Lombardi G, Ziemann E, Banfi G and Corbetta S: Physical activity-dependent regulation of parathyroid hormone and calcium-phosphorous metabolism. Int J Mol Sci 21: 5388, 2020.

13. Takeda S, Elefteriou F, Levasseur R, Liu X, Zhao L, Parker KL, Armstrong D, Ducy P and Karsenty G: Leptin regulates bone formation via the sympathetic nervous system. Cell 111: 305-317, 2002.

14. Hamano S, Tomokiyo A, Hasegawa D, Yuda A, Sugii H, Yoshida S, Mitarai H, Wada $\mathrm{N}$ and Maeda $\mathrm{H}$ : Functions of beta2-adrenergic receptor in human periodontal ligament cells. J Cell Biochem: 2020 (Online Ahead of Print).

15. Nijhuis LE, Olivier BJ, Dhawan S, Hilbers FW, Boon L, Wolkers MC, Samsom JN and de Jonge WJ: Adrenergic $\beta 2$ receptor activation stimulates anti-inflammatory properties of dendritic cells in vitro. PLoS One 9: e85086, 2014.

16. Mauro LJ, Wenzel SJ and Sindberg GM: Regulation of chick bone growth by leptin and catecholamines. Poult Sci 89: 697-708, 2010.

17. National Research Council Committee for the Update of the Guide for the Care and Use of Laboratory Animals: Guide for the Care and Use of Laboratory Animals. The National Academies Collection: Reports funded by National Institutes of Health. National Academies Press, Washington, DC, 2011.

18. Fathi E, Valipour B, Sanaat Z, Nozad Charoudeh H and Farahzadi R: Interleukin-6, -8 , and TGF- $\beta$ secreted from mesenchymal stem cells show functional role in reduction of telomerase activity of leukemia cell via $\mathrm{Wnt} 5 \mathrm{a} / \beta$-catenin and P53 pathways. Adv Pharm Bull 10: 307-314, 2020.

19. Fathi E, Farahzadi R, Javanmardi S and Vietor I: L-carnitine extends the telomere length of the cardiac differentiated CD117+-expressing stem cells. Tissue Cell 67: 101429, 2020.

20. Zhao ZQ, Liu WL, Guo SB, Bai R and Yan JL: Mechanism of methylprednisolone-induced primary cilia formation disorder and autophagy in osteoblasts. Orthop Surg 12: 645-652, 2020.

21. Dasu MR, Ramirez SR, La TD, Gorouhi F, Nguyen C, Lin BR, Mashburn C, Stewart H, Peavy TR, Nolta JA and Isseroff RR: Crosstalk between adrenergic and toll-like receptors in human mesenchymal stem cells and keratinocytes: A recipe for impaired wound healing. Stem Cells Transl Med 3: 745-759, 2014.

22. Huang X,Zhu B, Wang X, Xiao R and Wang C: Three-dimensional co-culture of mesenchymal stromal cells and differentiated osteoblasts on human bio-derived bone scaffolds supports active multi-lineage hematopoiesis in vitro: Functional implication of the biomimetic HSC niche. Int J Mol Med 38: 1141-1151, 2016.

23. Shen $\mathrm{C}$, Yang $\mathrm{C}$, Xu S and Zhao H: Comparison of osteogenic differentiation capacity in mesenchymal stem cells derived from human amniotic membrane (AM), umbilical cord (UC), chorionic membrane (CM), and decidua (DC). Cell Biosci 9: 17, 2019.

24. Heo SK, Noh EK, Gwon GD, Kim JY, Jo JC, Choi Y, Koh S, Baek JH, Min YJ and Kim H: LIGHT (TNFSF14) increases the survival and proliferation of human bone marrow-derived mesenchymal stem cells. PLoS One 11: e0166589, 2016.

25. Yin Y, Chen P, Yu Q, Peng Y, Zhu Z and Tian J: The effects of a pulsed electromagnetic field on the proliferation and osteogenic differentiation of human adipose-derived stem cells. Med Sci Monit 24: 3274-3282, 2018

26. Livak KJ and Schmittgen TD: Analysis of relative gene expression data using real-time quantitative PCR and the 2(-Delta Delta C(T)) method. Methods 25: 402-408, 2001

27. Chang B, Song W, Han T, Yan J, Li F, Zhao L, Kou H and Zhang Y: Influence of pore size of porous titanium fabricated by vacuum diffusion bonding of titanium meshes on cell penetration and bone ingrowth. Acta Biomater 33: 311-321, 2016.

28. Fares C, Hsu SM, Xian M, Xia X, Ren F, Mecholsky JJ Jr, Gonzaga $\mathrm{L}$ and Esquivel-Upshaw J: Demonstration of a $\mathrm{SiC}$ protective coating for titanium implants. Materials (Basel) 13: 3321, 2020 
29. Cardona MJ, Turner C, Ross C, Baird E and Black RA: An improved process for the fabrication and surface treatment of custom-made titanium cranioplasty implants informed by surface analysis. J Biomater Appl 35: 602-614, 2021

30. Scarano A, Lorusso F, Orsini T, Morra M, Iviglia G and Valbonetti L: Biomimetic surfaces coated with covalently immobilized collagen type I: An X-ray photoelectron spectroscopy atomic force microscopy, micro-CT and histomorphometrical study in rabbits. Int J Mol Sci 20: 724, 2019.

31. Gong T, Xie J, Liao J, Zhang T, Lin S and Lin Y: Nanomaterials and bone regeneration. Bone Res 3: 15029, 2015.

32. Dikicier E, Karaçaylı Ü, Dikicier S and Günaydın Y: Effect of systemic administered zoledronic acid on osseointegration of a titanium implant in ovariectomized rats. J Craniomaxillofac Surg 42: 1106-1111, 2014.

33. Liu Y, Hu J, Liu B, Jiang X and Li Y: The effect of osteoprotegerin on implant osseointegration in ovariectomized rats. Arch Med Sci 13: 489-495, 2017

34. Tsuchiya S, Sugimoto K, Kamio H, Okabe K, Kuroda K, Okido $\mathrm{M}$ and Hibi H: Kaempferol-immobilized titanium dioxide promotes formation of new bone: Effects of loading methods on bone marrow stromal cell differentiation in vivo and in vitro. Int J Nanomedicine 13: 1665-1676, 2018.

35. Carnagarin R, Matthews V, Zaldivia MTK, Peter K and Schlaich MP: The bidirectional interaction between the sympathetic nervous system and immune mechanisms in the pathogenesis of hypertension. Br J Pharmacol 176: 1839-1852, 2019.

36. Duncan CP and Shim SS: J. Edouard Samson address: The autonomic nerve supply of bone. An experimental study of the intraosseous adrenergic nervi vasorum in the rabbit. J Bone Joint Surg Br 59: 323-330, 1977

37. Mach DB, Rogers SD, Sabino MC, Luger NM, Schwei MJ Pomonis JD, Keyser CP, Clohisy DR, Adams DJ, O'Leary P and Mantyh PW: Origins of skeletal pain: Sensory and sympathetic innervation of the mouse femur. Neuroscience 113: 155-166, 2002.

38. Mediero A, Wilder T, Shah L and Cronstein BN: Adenosine $A_{2 A}$ receptor (A2AR) stimulation modulates expression of semaphorins $4 \mathrm{D}$ and $3 \mathrm{~A}$, regulators of bone homeostasis. Faseb J 32 3487-3501, 2018

39. Emet M, Ozcan H, Ozel L, Yayla M, Halici Z and Hacimuftuoglu A: A review of melatonin, its receptors and drugs. Eurasian J Med 48: 135-141, 2016.

40. Teong B, Kuo SM, Chen CH, Chen YK, Cheng ZJ and Huang HH: Characterization and human osteoblastic proliferation- and differentiation-stimulatory effects of phosphatidylcholine liposomes-encapsulated propranolol hydrochloride. Biomed Mater Eng 24: 1875-1887, 2014.

41. Bonnet N, Benhamou CL, Malaval L, Goncalves C, Vico L, Eder V, Pichon C and Courteix D: Low dose beta-blocker prevents ovariectomy-induced bone loss in rats without affecting heart functions. J Cell Physiol 217: 819-827, 2008.

42. Srinivasan AV: Propranolol: A 50-year historical perspective. Ann Indian Acad Neurol 22: 21-26, 2019.

43. Woroń J, Siwek M and Gorostowicz A: Adverse effects of interactions between antidepressants and medications used in treatment of cardiovascular disorders. Psychiatr Pol 53: 977-995, 2019.

44. Zhou HM, Zhong ML, Wang RH, Long CL, Zhang YF, Cui WY and Wang H: Synergisms of cardiovascular effects between iptakalim and amlodipine, hydrochlorothiazide or propranolol in anesthetized rats. Zhongguo Ying Yong Sheng Li Xue Za Zhi 31 532-540, 2015.

45. Stapleton MP: Sir James Black and propranolol. The role of the basic sciences in the history of cardiovascular pharmacology. Tex Heart Inst J 24: 336-342, 1997.

46. Wolter JK, Wolter NE, Blanch A, Partridge T, Cheng L, Morgenstern DA, Podkowa M, Kaplan DR and Irwin MS: Anti-tumor activity of the beta-adrenergic receptor antagonist propranolol in neuroblastoma. Oncotarget 5: 161-172, 2014.

47. Bustamante P, Miyamoto D, Goyeneche A, de Alba Graue PG, Jin E, Tsering T, Dias AB, Burnier MN and Burnier JV: Beta-blockers exert potent anti-tumor effects in cutaneous and uveal melanoma. Cancer Med 8: 7265-7277, 2019.

48. Bravo-Calderón DM,Assao A,GarciaNG,Coutinho-CamilloCM, Roffé M, Germano JN and Oliveira DT: Beta adrenergic receptor activation inhibits oral cancer migration and invasiveness. Arch Oral Biol 118: 104865, 2020.
49. Minkowitz B, Boskey AL, Lane JM, Pearlman HS and Vigorita VJ: Effects of propranolol on bone metabolism in the rat. J Orthop Res 9: 869-975, 1991

50. Wu H, Song Y, Li J, Lei X, Zhang S, Gao Y, Cheng P, Liu B, Miao S, Bi L, et al: Blockade of adrenergic $\beta$-receptor activation through local delivery of propranolol from a 3D collagen/polyvinyl alcohol/hydroxyapatite scaffold promotes bone repair in vivo. Cell Prolif 53: e12725, 2020.

51. Sato T, Arai M, Goto S and Togari A: Effects of propranolol on bone metabolism in spontaneously hypertensive rats. J Pharmacol Exp Ther 334: 99-105, 2010.

52. Sato T, Miyazawa K, Suzuki Y, Mizutani Y, Uchibori S, Asaoka R, Arai M, Togari A and Goto S: Selective $\beta 2$-adrenergic antagonist butoxamine reduces orthodontic tooth movement J Dent Res 93: 807-812, 2014.

53. Actis L, Gaviria L, Guda T and Ong JL: Antimicrobial surfaces for craniofacial implants: State of the art. J Korean Assoc Oral Maxillofac Surg 39: 43-54, 2013.

54. Jenei-Lanzl Z, Grässel S, Pongratz G, Kees F, Miosge N, Angele P and Straub RH: Norepinephrine inhibition of mesenchymal stem cell and chondrogenic progenitor cell chondrogenesis and acceleration of chondrogenic hypertrophy. Arthritis Rheumatol 66: 2472-2481, 2014.

55. Li H, Fong C, Chen Y, Cai G and Yang M: beta2- and beta3-, but not betal-adrenergic receptors are involved in osteogenesis of mouse mesenchymal stem cells via cAMP/PKA signaling. Arch Biochem Biophys 496: 77-83, 2010.

56. Li XL, Zeng D, Chen Y, Ding L, Li WJ, Wei T, Ou DB, Yan S, Wang B and Zheng QS: Role of alpha- and beta-adrenergic receptors in cardiomyocyte differentiation from murine-induced pluripotent stem cells. Cell Prolif 50: e12310, 2017.

57. Xiao L, Pimental DR, Amin JK, Singh K, Sawyer DB and Colucci WS: MEK1/2-ERK1/2 mediates alpha1-adrenergic receptor-stimulated hypertrophy in adult rat ventricular myocytes. J Mol Cell Cardiol 33: 779-787, 2001.

58. Marolt Presen D, Traweger A, Gimona $M$ and Redl H: Mesenchymal stromal cell-based bone regeneration therapies: From cell transplantation and tissue engineering to therapeutic secretomes and extracellular vesicles. Front Bioeng Biotechnol 7: $352,2019$.

59. Zhang W, Zhou L, Dang J, Zhang X, Wang J, Chen Y, Liang J, Li D, Ma J, Yuan J, et al: Human gingiva-derived mesenchymal stem cells Ameliorate Streptozoticin-induced T1DM in mice via suppression of $\mathrm{T}$ effector cells and Up-regulating Treg subsets. Sci Rep 7: 15249, 2017.

60. Reumann MK, Linnemann C, Aspera-Werz RH, Arnold S, Held M, Seeliger C, Nussler AK and Ehnert S: Donor site location is critical for proliferation, stem cell capacity, and osteogenic differentiation of adipose mesenchymal stem/stromal cells: Implications for bone tissue engineering. Int J Mol Sci 19: 1868, 2018.

61. Givogri MI, de Planell M, Galbiati F, Superchi D, Gritti A Vescovi A, de Vellis $\mathbf{J}$ and Bongarzone ER: Notch signaling in astrocytes and neuroblasts of the adult subventricular zone in health and after cortical injury. Dev Neurosci 28: 81-91, 2006.

62. Masaoutis $\mathrm{C}$ and Theocharis S: The role of exosomes in bone remodeling: Implications for bone physiology and disease. Dis Markers 2019: 9417914, 2019.

63. Wong SK, Chin KY and Ima-Nirwana S: The osteoprotective effects of kaempferol: The evidence from in vivo and in vitro studies. Drug Des Devel Ther 13: 3497-3514, 2019.

64. Rodrigues WF, Madeira MF, da Silva TA, Clemente-Napimoga JT, Miguel CB, Dias-da-Silva VJ, Barbosa-Neto O, Lopes AH and Napimoga MH: Low dose of propranolol down-modulates bone resorption by inhibiting inflammation and osteoclast differentiation. Br J Pharmacol 165: 2140-2151, 2012.

65. Smitham P, Crossfield L, Hughes G, Goodship A, Blunn G and Chenu C: Low dose of propranolol does not affect rat osteotomy healing and callus strength. J Orthop Res 32: 887-893, 2014.

This work is licensed under a Creative Commons Attribution-NonCommercial-NoDerivatives 4.0 International (CC BY-NC-ND 4.0) License. 